\title{
Crystal Structure of Catena-( $\left(\mu_{8}\right.$-benzene-1,2,4,5-tetracarboxylato)-triaqua- calcium(II)-copper(II))
}

\author{
Gaoxiang Meng, ${ }^{\dagger}$ Qiang LI, and Yongming YANG \\ School of Advanced Materials and Mechatronic Engineering, Hubei Minzu University, Enshi 44500, Hubei, \\ P. R. China
}

\begin{abstract}
The structure of catena- $\left(\left(\mu_{8}\right.\right.$-benzene-1,2,4,5-tetracarboxylato)-triaqua-calcium(II)-copper(II)) (I) was determine by X-ray crystallography. There is half of one benzene-1,2,4,5-tetracar-boxylate tetra-anion (BTA ${ }^{4-}$ ), each half $\mathrm{Cu}(\mathrm{II})$ and $\mathrm{Ca}(\mathrm{II})$ dications, and one and a half coordinated water molecules in its asymmetric unit. The compound crystallizes in the monoclinic $C 2 / \mathrm{c}$ space group and was characterized as follows: $a=14.1365(13) \AA, b=13.2077(12) \AA, c=8.8865(8) \AA$, $b=126.365(3)^{\circ}, V=1336.1(2) \AA^{3}, Z=4, T=150(2) \mathrm{K}$. The crystal structure was solved by direct methods and refined by full-matrix least-squares on $F^{2}$ to final values of $R_{1}=0.0779$ and $w R_{2}=0.1666$.
\end{abstract}

(Received April 16, 2019; Accepted May 16, 2019; Published on web August 10, 2019)

The construction of some metal-organic framework (MOF) based on alkaline earth metals and aromatic carboxylic acid has been emerging as a research field for more than thirty years. ${ }^{1}$ The lack of $d$-orbital electrons in alkaline elements may result in even more coordination geometries in the construction of a MOF material. ${ }^{1}$ However, by introducing both one transition and alkaline earth metals simultaneously into a MOF structure has been only reported recently. ${ }^{2}$ The unsaturated coordination and weak coordinated solvent molecules around metal centers can provide some new type of potentially valuable MOF materials..$^{3-6}$ Based on this design strategy, we have now prepared one $\mathrm{Cu}(\mathrm{II})-\mathrm{Ca}(\mathrm{II})$ combined coordination complex (I) under the hydrothermal condition (Fig. 1). In (I), these two types of metals are bridged by benzene-1,2,4,5-tetracarboxylic acid $\left(\mathrm{H}_{4} \mathrm{BTA}\right)$. Although no crystallographic void was detected in (I), it can adsorb $\mathrm{N}_{2}$ gas to a certain extent. Herein, we will

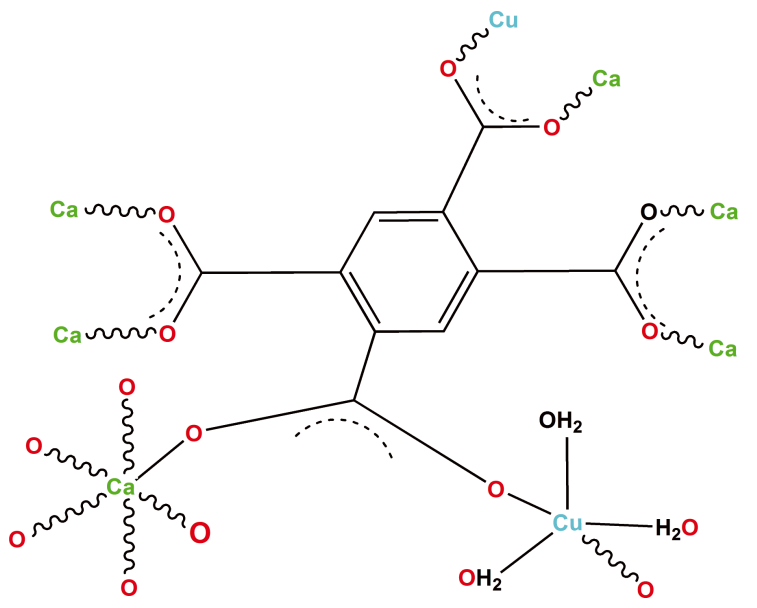

Fig. 1 Chemical diagram of the title compound (I).

$\dagger$ To whom correspondence should be addressed.

E-mail: gaoxiang_meng@126.com report the crystal structure of (I).

In this research, compound (I) was prepared by dissovling $\mathrm{Cu}\left(\mathrm{NO}_{3}\right)_{2} \cdot 2\left(\mathrm{H}_{2} \mathrm{O}\right) \quad(0.2 \mathrm{mmol}, 48.0 \mathrm{mg}), \mathrm{CaCl}_{2} \quad(0.2 \mathrm{mmol}$, $23 \mathrm{mg})$ and $\mathrm{H}_{4} \mathrm{BTA}$ acid $(0.2 \mathrm{mmol}, 51.0 \mathrm{mg})$ in $10 \mathrm{~mL}$ of water. The mixture was stirred for $10 \mathrm{~min}$ at ambient temperature and then heated in a $20-\mathrm{mL}$ capacity Teflon-lined reaction vessel at $160^{\circ} \mathrm{C}$ for 3 days. After slowly cooling to room temperature at a rate of $5^{\circ} \mathrm{C} \mathrm{h}^{-1}$, the final plate-blue crystals $(51.2 \mathrm{mg})$, suitable for X-ray structure analysis, could be obtained. The crystal and structure refinement data are summarized in Table 1.

Table 1 Crystal and experimental data

\begin{tabular}{|c|c|}
\hline $\begin{array}{l}\text { Chemical formula: } \mathrm{C}_{10} \mathrm{H}_{8} \mathrm{CaC} \\
\text { Formula weight }=407.78 \\
T=150(2)\end{array}$ & \\
\hline $\begin{array}{l}\text { Crystal system: monoclinic } \\
a=14.1365(13) \AA\end{array}$ & Space group: $C 2 / \mathrm{c}$ \\
\hline $\begin{array}{l}b=13.2077(12) \AA \\
c=8.8865(8) \AA\end{array}$ & $\beta=126.365(3)$ \\
\hline$V=1336.1(2)$ & $Z=4$ \\
\hline$D_{\mathrm{x}}=2.027 \mathrm{~g} / \mathrm{cm}^{3}$ & \\
\hline Radiation: Mo $K \alpha(\lambda=0.710$ & $3 \AA \AA$ \\
\hline$\mu($ Mo $K \alpha)=2.08 \mathrm{~mm}^{-1}$ & $F\left(\begin{array}{lll}0 & 0 & 0\end{array}\right)=820.0$ \\
\hline Crystal size $=0.05 \times 0.05 \times$ & $02 \mathrm{~mm}^{3}$ \\
\hline No. of reflections collected $=$ & 5798 \\
\hline No. of independent reflection & $=1185$ \\
\hline$\theta$ range for data collection: 4 & 24 to $50^{\circ}$ \\
\hline Data/Restraints/Parameters $=$ & $1185 / 6 / 106$ \\
\hline$R$ indices $[I \geq 2 \sigma(I)]: R_{1}=0$. & $779, w R_{2}=0.1637$ \\
\hline$R$ indices (all data) $R_{1}=0.08$ & $10, w R_{2}=0.1666$ \\
\hline Goodness-of-fit on $F 2=1.08$ & \\
\hline $\begin{array}{l}(\Delta / \sigma)_{\max }=0.001 \\
(\Delta \rho)_{\max }=0.97 \mathrm{e}^{-3}\end{array}$ & $(\Delta \rho)_{\min }=-1.55 \mathrm{e}^{-3}$ \\
\hline Measurement: Bruker Smart & PEX II CCD diffractometer \\
\hline Program system: SHELXTL & \\
\hline Structure determination: intri & sic phasing (SHELXT-2014/410) \\
\hline Refinement: full matrix least & quares (SHELXL-2014/711) \\
\hline CCDC deposition number: 1 & 00686 \\
\hline
\end{tabular}




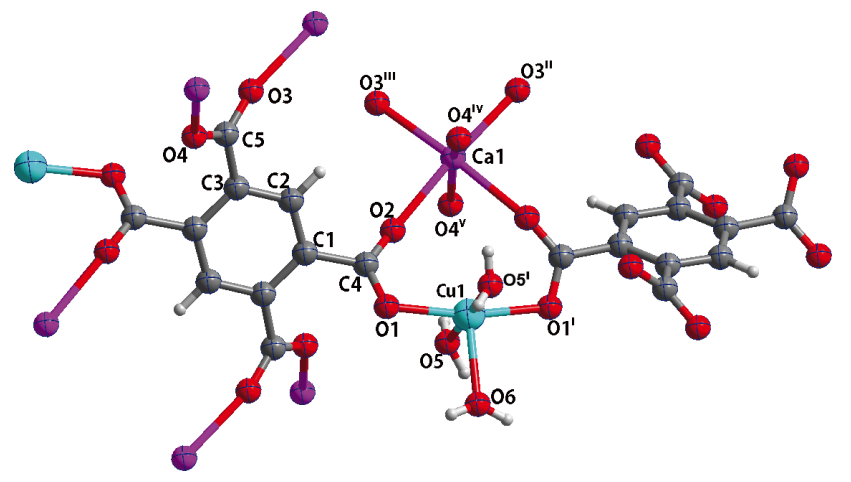

Fig. 2 Molecular structure of the title compound shown as $30 \%$ thermal probability. The symmetry codes in Fig. 2 meet those in Tables S1 and S2.

$\mathrm{H}$ atoms bonded to $\mathrm{C}$ atoms were positioned geometrically with $\mathrm{C}-\mathrm{H}=0.93 \AA$ (aromatic) and refined in a riding mode $\left[U_{\text {iso }}(\mathrm{H})=1.2 U_{\text {eq }}(\right.$ aromatic $\left.\mathrm{C})\right] . \quad \mathrm{H}$ atoms bonded to water oxygen atoms were initially found in difference maps and refined with constraints of $d_{\mathrm{O}-\mathrm{H}}=0.85(2) \AA$ and $U_{\text {iso }}(\mathrm{H})$ $=1.5 U_{\text {eq }}(\mathrm{O})$. In the final refinement, their positions were not satisfactorily converged and were then restrained. The relatively high $R$ and $w R$ values because of the bad diffraction quality of the slim crystal. Although we have tried our best several times to select better crystal samples for the X-ray diffraction experiment, we were unsuccessful each time. The highest peak of the residual electron density $\left(0.97 \mathrm{e}^{-3}\right)$ at $(0.00000 .0149$ $0.7500)$ is $1.06 \AA$ away from atom O6, and the deepest hole $\left(-1.55 \mathrm{e}^{-3}\right)$ at $(0.50000 .19790 .7500)$ is $1.47 \AA$ away from atom $\mathrm{H} 2$, respectively.

The asymmetric unit of (I) was composed of half a benzene1,2,4,5-tetracarboxylate tetra-anion (BTA ${ }^{4}$ ), each half a $\mathrm{Cu}(\mathrm{II})$ and $\mathrm{Ca}(\mathrm{II})$ dications both lying on a two-fold axis, and one and a half coordinated water molecules (Fig. 2). The two lateral carboxylate planes $(\mathrm{C} 4 / \mathrm{O} 1 / \mathrm{O} 2$ and $\mathrm{C} 5 / \mathrm{O} 3 / \mathrm{O} 4)$ on the benzene group are twisted $60.7(1)^{\circ}$ away from each other. The $\mathrm{Cu}(\mathrm{II})$ center adopted a slightly distorted square-pyramidal coordination polyhedron $(\tau=0.16) .^{7} \quad$ Two carboxylate $\mathrm{O} 1$ oxygen atoms from the BTA ${ }^{4-}$ anion and two $\mathrm{O} 5$ water molecules constitute the base plane, and the water oxygen $\mathrm{O} 6$ atom resides on the vertex of the square-pyramid. The $\mathrm{Cu}$ (II) atom is $c a$. $0.11 \AA$ above away from the base plane. The $\mathrm{Cu}-\mathrm{O}_{\text {base plane }}$ bond lengths (1.970(8) $\AA$ and 2.019(6) $\AA$ ) are significantly shorter than the vertical $\mathrm{Cu}-\mathrm{O} 6$ bond $(2.248(13) \AA)$. This should be largely attributed to the spatial hindrance and the Jahn-Teller effect of the electron orbitals of the $\mathrm{Cu}$ (II) atom. Regarding the calcium atom, it was coordinated by three pairs of carboxylate oxygen atoms from six separated $\mathrm{BTA}^{4-}$ anions, resulting in a distorted octahedral environment. These $\mathrm{Ca}-\mathrm{O}$ bond distances and $\mathrm{O}-$ Ca-O angles range from 2.267(7) to 2.328(7) $\AA$ and from 81.2(3) to $176.1(3)^{\circ}$, respectively (Table $\mathrm{S} 1$ ), which are comparable to some analogs. ${ }^{11}$ Two adjacent $\mathrm{Cu}(\mathrm{II})$ and $\mathrm{Ca}$ (II) cations bridged by a $\mu_{2}-\mathrm{COO}^{-}$group is of 3.961(2) $\AA$ between them. Also two neighboring $\mathrm{Ca}(\mathrm{II})$ atoms linked by a carboxylate group are of 5.103(2) ̊ away from each other. As a whole, two $\mathrm{Cu}$ (II) and six $\mathrm{Ca}(\mathrm{II})$ cations were linked by one $\mathrm{BTA}^{4-}$ anion, resulting an alternative arrayed viewed along the [001] axis.

In the crystal packing, a complex three-dimensional metal coordination network was formed, which was further consolidated by three O-H...O hydrogen bonds (Table S2). For a simplified topological understanding, the $\mathrm{Cu}$ (II), $\mathrm{Ca}$ (II) cations and $\mathrm{BTA}^{4-}$ anion in (I) has been been regarded as being independent two-, six- and eight-connected nodes, respectively. Thus, the whole coordination network can be finally viewed as a 6,8-connected net with the Schläfli symbol of $\left\{3.4^{13} \cdot 6\right\}$ $\left\{3^{2} \cdot 4^{8} \cdot 5^{9} \cdot 6^{7} \cdot 7^{2}\right\}$ by analysis of the program TOPOS 4.0 (Fig. S1). ${ }^{8}$ To evaluate the adsorbability of compound (I), a $\mathrm{N}_{2}$ gas adsorption experiment was performed at ambient temperature. Although no apparent crystallographic void was detected by an analysis of the program PLATON, ${ }^{9}$ the results indicate that compound (I) can efficiently adsorb $\mathrm{N}_{2}$ gas to a certain extent under the tested condition with a BET surface area and Langmuir areas of $c a .63 .0 \mathrm{~m}^{2} \mathrm{~g}^{-1}, 98.2 \mathrm{~m}^{2} \mathrm{~g}^{-1}$, respectively (Fig. S2), and the pore volume in (I) is about $0.10 \mathrm{~cm}^{3} \mathrm{~g}^{-1}$. The $\mathrm{N}_{2}$ adsorption of (I) may be related to the release of the weak coordinating of water molecules in (I). Further research on the mechanism will be conducted in our lab.

\section{Supporting Information}

This material is available free of charge on the Web at http:// www.jsac.or.jp/xraystruct/.

\section{Acknowledgements}

This work is supported by the $\mathrm{Ph}$. D. Programs Foundation of Hubei Minzu University (No. MY2015B012).

\section{References}

1. V. A. Uchtman and R. J. Jandacek, Inorg. Chem., 1980, 19, 350.

2. M. John Platers, R. Alan Howie, and A. J. Roberts, Chem. Commun., 1997, 893.

3. P. C. Liang, H. K. Liu, C. T. Yeh, C. H. Lin, and V. Zima, Cryst. Growth Des., 2011, 11, 699.

4. D. Banerjee, Z. Zhang, A. M. Plonka, J. Li, and J. B. Parise, Cryst. Growth Des., 2012, 12, 2162.

5. P. C. Cheng, F. S. Tseng, C. T. Yeh, T. G. Chang, C. C. Kao, C. H. Lin, W. R. Liu, J. S. Chen, and V. Zima, CrystEngComm, 2012, 14, 6812.

6. R. K. Vakiti, B. D. Garabato, N. P. Schieber, M. J. Rucks, Y. Cao, C. Webb, J. B. Maddox, A. Celestian, W.-P. Pan, and B. Yan, Cryst. Growth Des., 2012, 12, 3937.

7. A. W. Addison, T. N. Rao, J. Reedijk, J. van Rijn, and G. C. Verschoor, J. Chem. Soc. Dalton Trans., 1984, 1349.

8. V. A. Blatov, A. P. Shevchenko, and V. N. Serenzhkin, Acta Crystallogr. A, 1995, 51, 909.

9. A. Spek, J. Appl. Crystallogr., 2003, 36, 7.

10. G. M. Sheldrick, Acta Crystallogr. A, 2008, 64, 112.

11. G. M. Sheldrick, Acta Crystallogr. C, 2015, 71, 3. 